\title{
Estabilidade e reintegração
}

\author{
S. Soares de Faria
}

1 - Discorrendo a legislação trabalhista, desde a pioneira, que foi a lei 4682 , de 24 de janeiro de 1923, até a mais recente, não vislumbraremos nenhuma lei que tenha, implicita ou explicitamente, feito referencia à reintegração do empregado com direito à estabilidade, que haja sido demitido, a despeito e contra a proibição legal.

$\mathrm{O}$ art. 42 da lei 4682 estatuio simplesmente que, depois de $\operatorname{dez}$ anos de serviços efetivos, o empregado das empresas ferroviarias só poderia ser demitido

no caso de falta grave verificada em inquerito administrativo.

Não ha referencia alguma à reintegração, no caso de violação da lei. Tambem a ela se não referiu o art. 43 da lei 5109, que tornou extensivos às empresas de portos e navegação os favores consubstanciados na lei 4682 .

2 - Ao revez do que vem sido afirmado, o decreto 20465 de $10^{\circ}$ de Outubro de 1931 não consignou explicitamente a reintegração, no caso de ser o empregado demitido. Previo hipótese diversa, que com a demissão se não confunde. Aqui se trata da possibilidade de ser o empregado suspenso, enquanto se processa o inquérito para que se apurem as acusações contra ele arguidas.

Determina o $\S 20^{\circ}$ que, no caso de reconhecer o Conselho Nacional do Trabalho 
a não existência de falta grave, fica a empresa obrigada a readmití-lo ao serviço e a indenisá-lo dos salarios durante o período da suspensão.

Observe-se que o inciso não fala em demissão e suspender é um áto de mero afastamento, determinado pela acusação, pondo a mira em não criar dificuldades ao andamento da perquirição. A suspensão é áto preliminar, que não implica em desligamento definitivo do empregado, sobre cuja conduta se arguiram faltas graves. A demissão é áto definitivo, que importa em radiar o acusado do quadro dos servidores da empresa.

Não reconhecida a culpabilidade, cessam os efeitos da suspensão. O acusado reassume o cargo, do qual fora temporariamente afastado, que não de modo definitivo. A falta de técnica do contexto é evidente, quando fala em readmissão, pois, na hipótese nele prefigurada, não se cogitára de afastamento definitivo. O acusado mantinha-se no cargo, uma vez cessado o motivo do seu afastamento, como se nunca dele se houvera separado. A lei em apreço cogitou tão somente de suspensão, afastamento temporário, e não de demissão, que são conceitos diferentes e diversos, de sorte que em reintegração, no caso de demissão, a lei, no passo invocado, silenciou por completo.

3 - As que se lhe seguiram, não discrepam da sua orientação. $\mathrm{O}$ art. $^{\circ} 89$ do decreto $n .^{\circ} 22872$, de 29 de junho de 1933, que creou o Instituto de Aposentadoria e Pensões dos Marítimos, nem siquer se referio à readmissão, apenas garantindo o direito à efetividade no cargo, sem prever a hipótese de demissão, e muito menos a de reintegração.

O art. ${ }^{\circ} 15$ do Dec. n. ${ }^{\circ} 24615$, de 9 de julho de 1934, que determinou a creação do Instituto de Aposentadoria e Pensões dos Bancários, ao tratar da estabilidade dos empregados, tambem não foi explicito a respeito, por ter cogitado, apenas, do caso de suspensão, como o fizera o dec. 20465. 
O Decreto n. 24273 de 22 de maio de 1934, que mais de perto nos interessa, por ser o instituidor, para os comerciários, das regalias a outras classes já atribuidas, no seu art.o 33, dispoz que

a demissão, ou redução de vencimentos dos empregados e operarios que contarem mais de dez anos de serviço efetivo na mesma casa comercial, só será permitida, depois da publicação deste decreto, por motivo de falta grave, desobediencia, indisciplina ou circunstâncias de força maior devidamente comprovada.

Não se referiu à suspensão, nem à reintegração, não cogitando nem assegurando ao comerciario a estabilidade completa, vale dizer o direito ao cargo, mesmo contra a vontade do empregador, pois, no $\S$ unico a esse artigo, presupôs a demissão, com o sujeitar o patrão às sanções do art.o 13 do decreto $n .^{\circ} 19770$ de 19 de março de 1931, ou seja à pena

de pagar a indenisação correspondente ao salario ou ordenado de seis mezes.

Assinale-se, de relance, que esse decreto, no $\S$ invocado, distingue perfeitamente o caso de demissão do de suspensão, átos que, na verdade, não podem ser confundidos, e ainda põe de manifesto que a demissão é possivel, mesmo no caso

de operario ou empregado garantido pelo direito de vitaliciedade,

caso em que se não dará a reintegração, mas se resolverá em uma indenisação

correspondente a cinco anos de salario ou de ordenado. 
E' o que está e, agora sim explicitamente, consignado no $\S 2 .^{\circ}$ ao mesmo artigo. A demissão, mesmo contrária ao mandamento legal, não implica em reintegração, mas converte-se em uma pena ou em uma indenisação. E' a orientação do nosso direito, que a legislação trabalhista adotou.

4 - Essa determinação permaneceu em vigor, não tendo sido afetada pelo decreto 183 de 26 de Dezembro de 1934, que aprovou o regulamento para o Instituto de Aposentadoria e Pensões para os Comerciarios. Ao contrário, em passo algum do regulamento se observa qualquer rebeldia, a que seria, si houvesse, inaceitavel, ao disposto naquele diploma. Nem pela lei n. 62, tanto assim que, só em 1937, com a promulgação da lei 502 de 11 de setembro, foi aquele preceito expressamente revogado.

5 - A lei n. 62 não discrepa das anteriores. Reproduziu mesmo os seus dispositivos, no que se refere ao assunto, sem qualquer modificação. $O$ preceito do seu art. ${ }^{\circ} 10$ é $O$ mesmo que as outras proclamaram, pois estabelece a proibição, sem cogitar explicitamente da reintegração do demitido. E, não o tendo feito, certo é que se não afastou da orientação vigente, que, proibindo a demissão, fóra dos casos legaes, admitia a convolação da transgressão em pena pecuniaria, vale dizer não impunha a reintegração, mas a: compensava pela forma estatuida.

6 - Até aqui, perlustrando a legislação trabalhista, puzemos inteiramente de manifesto que nenhum dos seus diplomas estatuira a reintegração, de modo explicito, como consequencia da demissão do empregado, já no goso da estabilidade, contravindo a proibição legal. Nem implicitamente se poderá desumir essa garantia, porque, no que tange aos comerciarios, esteve em vigor o princípio oposto, isto é, o de poder o empregador fugir à estabilidade, mediante indenisação, de modo expresso e irrefragavel, por força da 
remissão do $\S$ unico do art. $^{\circ} 33$ do Decreto $n .^{\circ} 24.273$, pelo menos até 1937, quando foi declarado revogado aquele dispositivo.

7 - $\Theta_{\mathrm{s}}$ argumentos invocados, em contrário, não convencem. Porque a lei, vedando a demissão do empregado, não estatuiu, como consequencia inelutavel, a reintegração; ao contrário, previo a substituição por uma indenisação equivalente a seis mezes de ordenado ou de salarios. Esbarrando-se, assim, o argumento que se ergue, tendo por sucedaneo a nulidade da demissão, porque foi a propria lei que cominou uma pena especial, que esteve em vigor, até ser revogada em 1937 .

8 - A invocação do disposto na letra $f$ do $\operatorname{art.}^{\circ} 137$ da Constituição Federal não altera a situação. Si aquele dispositivo estabeleceu, como parece a alguns propugnadores da teoria do direito ao cargo, e não a de um direito à indenisação, perfeita e clara distinção entre a estabilidade e a indenisação proporcional aos anos de serviço, certo é que relegou à lei ordinaria a competente regulamentação. E, enquanto não vier essa lei, vigorarão os preceitos anteriores, porque a Constituição assim o quiz, com o não determinar que aquela regra entrasse desde logo em vigor. Si outro fosse o pensamento do legislador, por certo o teria abertamente declarado, como o fez, por exemplo, nos casos dos arts. 156 e 160 .

9 - Muito menos socorre, aos adversarios da indenisação como sucedaneo da condenação, a similitude que procuram estabelecer com o que se passa, nas repartições administrativas, pois, o funcionario demitido ilegalmente não tem direito ao cargo, mas aos proventos correspondentes. E' certo que a Constituição de 1934 tomou rumo diverso, contrariando a orientação do nosso direito, mas o preceito do art. ${ }^{\circ}$ não se transplantou para a Constituição de 
1937, e a teoria, que lograra infiltrar-se naquele inciso, teve direção efemera.

E' a lição do douto Trto Prates, como se vê dos trechos seguintes de sua obra "Direito Administrativo":

"A tendencia do direito administrativo moderno é no sentido de não reconhecer ao funcionario administrativo um direito subjetivo - pessoal - ao exercício do emprego ou cargo. 0 funcionario ilegalmente afastado de suas funções terá direito a indenisação, a ver respeitados os seus direitos patrimoniais: não, porem, à reintegração ao exercício do seu cargo. A maiorabilidade é prerrogativa dos magistrados. (ob. cit. n. ${ }^{\circ}$ 94).

E logo adiante

“A dominante deve ser o ínteresse publico, e não o direito do funcionario ao exercício do cargo. No Brasil, com a supressão do dispositivo contido no art.o 173 da Constituição de 1934, que mandara reintegrar o funcionario, cujo afastamento fivesse sido invalidado, e destituia de plano o que houvesse sido nomeado em seu logar, e com a disponibilidade estatuida pelo art. ${ }^{\circ} 157 \mathrm{da}$ Constitùição de 1937, parece que o direito caminha para uma concepção diversa da anterior, enquanto ao direito ao emprego é à consequente obrigação de manter a administração o funcionario no exercício do cargo".

10 - O fato de ter o direito privado consignado várias modalidades de cumprimento compulsorio de obrigação pessoaes, não significa a subversão do principio geral que nos herdou o direito romano e foi consagrado uma nova legislação civil. A regra geral subsiste. As execuções não a 
invalidam. Ademais, quer na renovação das locações comerciaes, quer nas vendas de terrenos adquiridos a prazo, como em outras hipóteses, que possam enquadrar-se no art. ${ }^{\circ}$ 1006 do Cod. de Processo Civil, não se trata de uma prestação pessoal de serviços, mas de uma obrigação que pode ser executada, independentemente da intenção do obrigado, cessando as relações por força da coação judicial. Não ha, evidentemente, consimilhança nas hipóteses.

A recusa em reintegrar o empregado transforma-se na obrigação de indenisar, nos termos do art. ${ }^{\circ} 880$ do Codigo Civil.

11 - Ficam, por essa forma, desfeitos, um a um, os argumentos do parecer do consultor jurídico do Ministerio do Trabalho, (Legislação do Trabalho n. ${ }^{\circ}$ 551, pag. 518) que determinou a mudança de orientação do Ministro a propósito do assunto, apartando-se de decisão anterior, seguramente fundamentada. A verdade está, no entanto, com a primeira atitude. Não se compreende a imposição de recolher o empregador o empregado que, bem ou mal, desmereceu da sua confiança. A prevalencia dessa orientação ocasionaria tantos maleficios à marcha regular das organisações comerciaes e industriaes, que os seus propugnantes teriam de render-se à evidencia inalmogavel dos fátos. $\mathrm{Si}$, como já se evidenciou, o Estado, em relação a seus funcionarios, pode não submeter-se à reintegração, como impor às empresas particulares essa medida, sem deixar-lhes a possibilidade de evitar os seus precalços, pelo meio legal da indenisação?

A lição que nos oferece a Hespanha, a respeito do assunto, deve ser objeto de larga meditação. A legislação trabalhista daquele país impoz a reintegração forçada, sem recurso à indenisação, embora o tivesse feito tão somente em relação a poucas categorias de empresas. Durou pouco, porem, a imposição, pois o criterio não prevaleceu e, por decreto de 20 de Dezembro de 1934, completado por disposição de 12 de Janeiro de 1935, foi restabelecido o direito 
de opção dos patrões, entre readmitir o empregado indesejavel, ou livrar-se dele pagando-lhe a indenisação fixada pela lei. (Gallar y Folch., pg. 86).

12 - À vista do exposto, impõe-se esta conclusão: No estado atual da legislação, não ha preceito que, explicita ou implicitamente, obrigue o empregador a readmitir, contra sua vontade, o empregado injustamente despedido, mesmo que conte mais de dez anos de serviço. A sua obrigação resolve-se em outra, na de indenisar, e essa indenisação, na hipótese, é a prevista no art. $^{\circ} 33 \S$ unico do decreto 24273, de 22 de maio de 1934, ou a prevista em leis subsequentes.

São Paulo, 11 de julho de 1942. 